\title{
Visualization of early events in mRNA vaccine delivery in non-human primates via PET-CT and near-infrared imaging
}

\author{
Kevin E. Lindsay ${ }^{1,5}$, Sushma M. Bhosle ${ }^{1,5}$, Chiara Zurla ${ }^{1,5}$, Jared Beyersdorf ${ }^{1}{ }^{1}$, Kenneth A. Rogers ${ }^{2}$, \\ Daryll Vanover ${ }^{1}$, Peng Xiao ${ }^{2}$, Mariluz Araínga ${ }^{2}$, Lisa M. Shirreff ${ }^{2}$, Bruno Pitard ${ }^{3}$, Patrick Baumhof ${ }^{4}$, \\ Francois Villinger ${ }^{2}$ and Philip J. Santangelo ${ }^{1 \star}$
}

\begin{abstract}
Visualization of the spatio-temporal trafficking of vaccines after their delivery would help evaluate the efficacy of candidate formulations and aid their rational design for preclinical and translational studies. Here, we show that a dual radionuclide-nearinfrared probe allows for quantitative, longitudinal and non-invasive monitoring, via positron emission tomography-computed tomography and near-infrared imaging of cynomolgus macaques, of the trafficking dynamics to draining lymph nodes of a model messenger RNA vaccine labelled with the probe. After intramuscular administration of the vaccine to the monkeys, we observed the dynamics of the mRNA vaccine at the injection site and in the draining lymph nodes, performed cellular analyses of the involved tissues using flow cytometry and identified through immunofluorescence that professional antigen-presenting cells are the primary cells containing the injected mRNA and encoding the antigen. This approach may reveal spatio-temporal determinants of vaccine efficacy in preclinical and translational studies employing large mammals.
\end{abstract}

$\mathrm{N}$ on-invasive approaches to longitudinally monitor vaccine responses and efficacy in a reliable manner are urgently needed. Current vaccine efficacy prediction metrics (known as correlates of protection) are often dependent on host-responses that take months to develop ${ }^{1}$ and are invasive in nature. The requisite gap between administration and evaluation ${ }^{2}$ may result in potential infection with the pathogen of concern before vaccine protection is verified.

In-vitro-transcribed (IVT) messenger RNA has garnered considerable interest as a biotechnology method. The short-lived nature of mRNA provides an inherent safety advantage over DNAbased approaches as the transcripts are unlikely to enter the nuclear compartment and cannot integrate into genomic DNA. Critically, mRNA-based vaccines are particularly attractive due to their simplicity of design and production, which allows the medical community to respond quickly and at scale to mutating and emerging pathogens. They are also highly amenable to personalized therapy, such as for various cancers ${ }^{3}$.

In the context of RNA vaccine development, a balance between expression of the epitopes that host immunity needs to target and immune stimulation is required to develop adaptive immunity and protection ${ }^{4}$. Efficacious mRNA vaccines often contain adjuvants that are used in tandem with mRNA to stimulate directed innate responses that drive the appropriate adaptive immunity ${ }^{5,6}$. In addition to protecting mRNA from nucleases, delivery vehicles such as lipid nanoparticles can be considered adjuvants, as they are not immunologically inert and demonstrate innate stimulating properties independent of the complexed $\mathrm{mRNA}^{7,8}$. The use of adjuvants with mRNA to elicit protection has been demonstrated, among others, in animal models of vaccines to $\mathrm{Flu}^{9}$ and $\mathrm{Zika}^{10}$ viruses, and cancer ${ }^{3}$. However, to date no mRNA-based vaccine has successfully demonstrated protection in a phase III clinical trial ${ }^{3}$.

It is apparent that a vaccine or therapeutic agent can only be effective if it localizes to the relevant tissues that require the intervention. After intramuscular (i.m.) or intradermal administration of mRNA, dendritic cells, which when activated migrate to draining lymph nodes (LNs), have a strong proclivity for uptake of mRNA $^{11}$, whether naked ${ }^{12}$ or encapsulated in lipid nanoparticles ${ }^{5,13}$. The complex immune milieu that ultimately develops requires the expression and presentation of antigens to lymph-node-based B and $\mathrm{T}$ cells for robust humoral and cell-mediated adaptive immunity to develop ${ }^{14}$. Multiple delivery routes (intraperitoneal, intravenal, i.m. and intradermal) are typically evaluated for a given adjuvant/ delivery vehicle formulation on the basis of their ability to generate differential correlates of protection ${ }^{15,16}$. In addition, off-target delivery to unintended organs should be thoroughly investigated due to safety concerns.

New non-invasive strategies that allow precise monitoring of mRNA after delivery in large mammals (that is, non-human primates and humans) would prove a useful tool to rapidly screen, evaluate and compare potential vaccine formulations. No such systemic and non-invasive methodology for clinical investigations exists at present. In preclinical studies, light scattering by tissues impedes the utility of commonly deployed optical-imaging methodologies, such as luminescence and fluorescence, in larger animal models. Invasive molecular tagging techniques, such as barcoding, are useful tools to investigate drug distribution but they would be even more powerful if used in combination with an unbiased systemic imaging approach.

Here, we demonstrate the use of positron emission tomographycomputed tomography (PET-CT) imaging as a non-invasive means

'Wallace H. Coulter Department of Biomedical Engineering, Georgia Tech and Emory University, Atlanta, GA, USA. ${ }^{2}$ New Iberia Research Center, University of Louisiana at Lafayette, Lafayette, LA, USA. ${ }^{3}$ CRCINA, INSERM, University of Nantes, University of Angers, Nantes, France. ${ }^{4}$ CureVac AG, Tübingen, Germany. ${ }^{5}$ These authors contributed equally: Kevin E. Lindsay, Sushma M. Bhosle, Chiara Zurla. *e-mail: philip.santangelo@bme.gatech.edu 


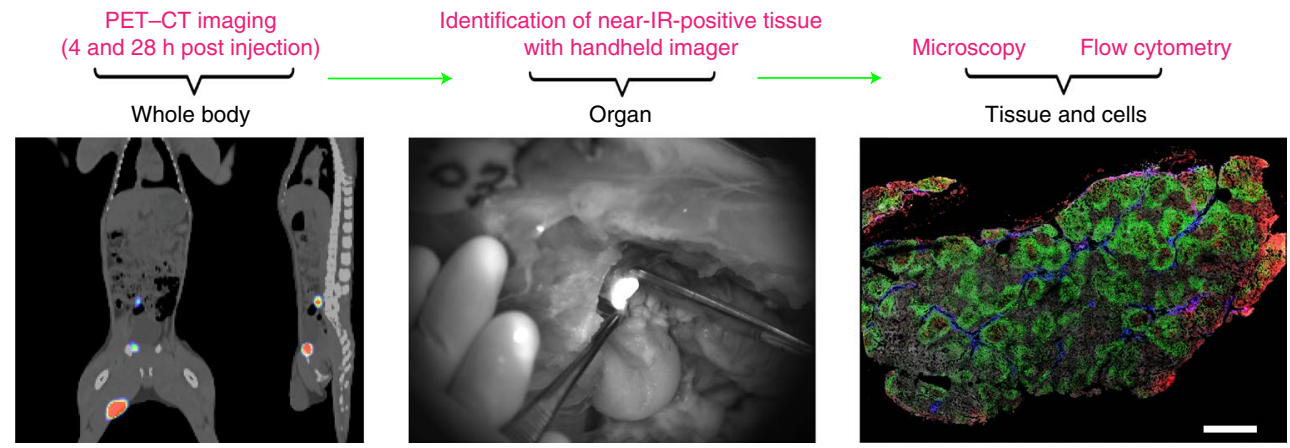

Fig. 1 | Experimental workflow and outline after i.m. injection with YF prME mRNA labelled with ${ }^{64} \mathrm{Cu}$-DyLight 680 . Whole-body PET-CT imaging was performed at 4 and $28 \mathrm{~h}$ following i.m. injection with ${ }^{64} \mathrm{Cu}$-DyLight 680 -labelled YF prME mRNA. Two animals were sacrificed at $28 \mathrm{~h}$ and the mRNApositive tissues were identified with a portable near-IR camera and extracted. The extracted tissues were then examined at the cellular level by microscopy and flow cytometry. The images in the figure illustrate the data collected at each step of the experiment. Scale bar, $750 \mu \mathrm{m}$.

to monitor the trafficking of a model mRNA vaccine to draining LNs in cynomolgus macaques in a quantitative manner. We chose yellow fever (YF) prME mRNA as a model system, as the live, attenuated $17 \mathrm{D}$ virus vaccine provides robust and widespread protection, and as such represents a gold standard to evaluate and compare experimental vaccines. We directly labelled the mRNA with an orthogonal dual PET-near-infrared (IR) probe, an approach agnostic to formulation, carrier or route of delivery. The mRNA was complexed with lipid derivatives of natural amino sugars used to deliver RNA structures $^{17-19}$ and delivered via i.m. injection, which is the most common route of delivery for vaccines in humans. By choosing ${ }^{64} \mathrm{Cu}$, a radioisotope with a half-life of $12.7 \mathrm{~h}$, we reasoned that any vaccine formulation could be tracked for days following administration.

The first $28 \mathrm{~h}$ of mRNA trafficking dynamics with high spatio-temporal resolution were monitored using PET-CT (Fig. 1 and Supplementary Video). Substantial signal in draining LNs was observed in three anatomical regions at $4 \mathrm{~h}$ post injection and it increased over the next $28 \mathrm{~h}$ by an average of $70 \%$. Subsequently, near-IR fluorescence and flow cytometry confirmed the systemiclevel events indicated by PET imaging and identified the cell types involved in vaccine uptake at the injection site and in the draining lymphoid organs. Confocal microscopy was used to investigate the mRNA distribution and protein expression within tissues and at the cellular level. We believe that this study establishes PET imaging as a viable modality to monitor and characterize the delivery of mRNA therapeutics and vaccines in large mammals, and thus has potential implications for preclinical and clinical mRNA studies.

\section{Results}

${ }^{64} \mathrm{Cu}$-DyLight 680 labelling of YF prME mRNA and i.m. injection. We previously demonstrated the orthogonal fluorescent labelling of IVT mRNA through the use of tetravalent NeutrAvidin-oligonucleotide complexes (multiply labelled tretravalent RNA imaging probes, MTRIPS) that target the $3^{\prime}$ untranslated region (UTR) of a gene ${ }^{20-22}$, achieving sufficient signal-to-noise ratios without compromising translational capacity or stimulating immune responses. Here, in addition to fluorescently labelling the oligos, we conjugated the divalent cationic chelator DOTA to the NeutrAvidin protein core (Fig. 2a). The resulting probes contained two components: DyLight 680-labelled oligos complementary to the $3^{\prime}$ UTR of the mRNA for near-IR imaging and NeutrAvidin core labelled with the chelator DOTA for whole-body PET-CT.

The probes were labelled with the radionuclide PET reporter ${ }^{64} \mathrm{Cu}$ and annealed to the mRNA $3^{\prime}$ UTR at a mRNA-to-probe molar ratio of 1:0.5, as optimized through size exclusion highperformance liquid chromatography (data not shown). Efficient protein expression and negligible innate immune activation were confirmed through in vitro transfection (Fig. $2 b-d$ ), with respect to unlabelled mRNA. Before injection, the ${ }^{64} \mathrm{Cu}$-DyLight 680-labelled YF prME mRNA was complexed with the aminoglycoside lipidic derivative CholK containing a kanamycin polar head group and a cholesterol moiety as a hydrophobic portion. We have previously demonstrated that mRNA complexed with CholK, at low mRNAto-nanoparticle charge ratios (0.1), enters cells via clathrin-mediated endocytosis and is released from the endosomal system and translated efficiently in vivo ${ }^{22}$.

PET-CT characterization of IVT-mRNA spatial distribution. To assess the bio-distribution of the model mRNA vaccine, four cynomolgus monkeys $(6-8 \mathrm{~kg})$ were injected with $200 \mu \mathrm{g}(0.8 \mathrm{mCi}$ in a total volume of $500 \mu \mathrm{l}$ Ringer's lactate solution) CholK-formulated YF prME mRNA in the right quadriceps. The animals were imaged via whole-body PET-CT at 4 and $28 \mathrm{~h}$ post injection in a clinical grade scanner. PET-CT images of animal AFO32 at $4 \mathrm{~h}$ post immunization have been used to illustrate the general results observed at the injection site and draining LNs (Fig. 3a). The labelled mRNA was clearly visible at the site of injection in the right quadriceps as well as in three draining LN regions: inguinal, iliac and para-aortic. At $4 \mathrm{~h}$ post injection, the signal magnitude in a given LN decreased with Euclidian distance from the injection site (Fig. 3b). The distance between the injection site and the most distal para-aortic LN was $9.2 \mathrm{~cm}$. This observation, combined with known draining patterns, indicates that the order of trafficking from the injection site is inguinal, iliac, then para-aortic, all confined to the ipsilateral side of the injection.

The exact number and connections between LNs within an anatomical chain varies per animal. As a result, if the signal contrast is appropriately enhanced, numerous LNs within an anatomical region can be resolved-for example, animal AFO32 displayed two draining iliac LNs (Fig. 3c). For the purpose of quantification and comparison, these individual LNs were grouped according to anatomical regions into single entities in subsequent analyses (that is, the two draining iliac LNs of AFO32 are reported as a single iliac LN).

These consistent trafficking patterns were confirmed at $28 \mathrm{~h}$ post immunization. Figure 4 shows the four relevant anatomical regions of each animal, presented from the anterior to the posterior, all with equal contrast enhancement.

Longitudinal PET-CT monitoring of mRNA trafficking. The distribution of labelled mRNA over time was assessed by measuring the changes in the PET signal with time, as highlighted through heat-map profiling of the maximum standard uptake value (SUV; radioactivity normalized to dose and body weight) intensity at the 
a

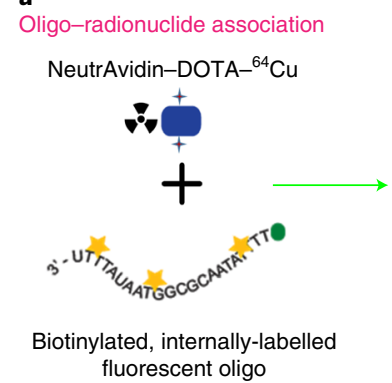

Oligo hybridization

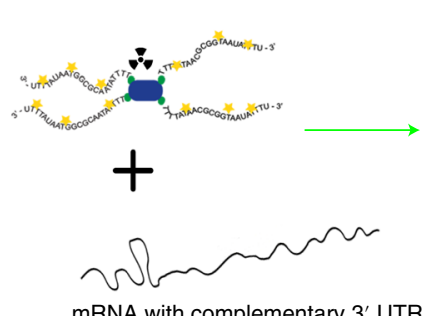

mRNA with complementary $3^{\prime}$ UTR
Nanoparticle encapsulation

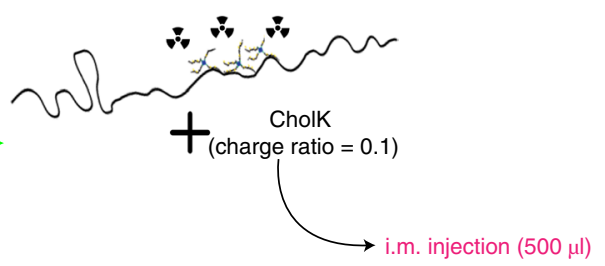

b

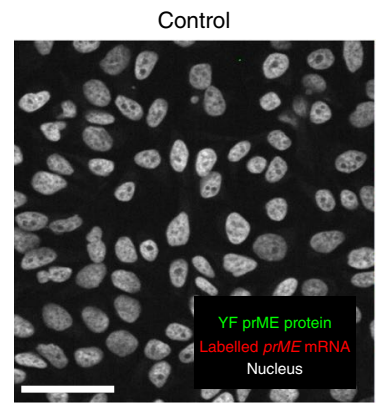

Fluorescently labelled mRNA
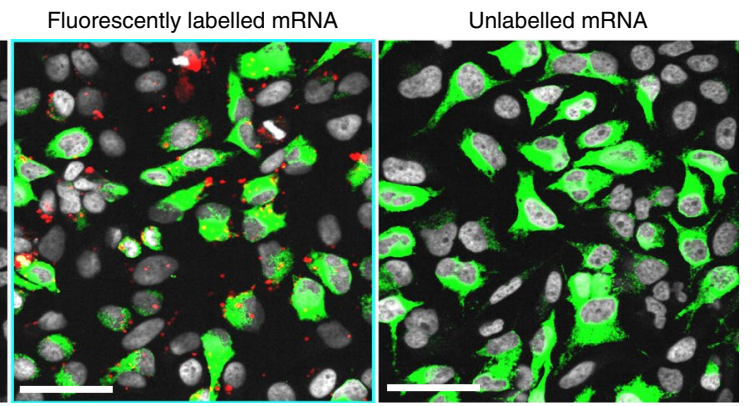

c

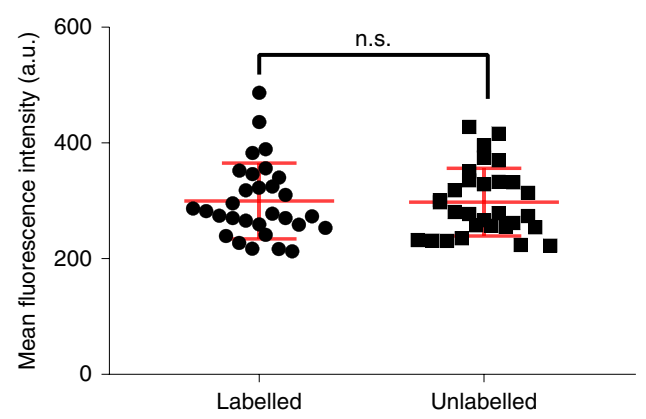

d

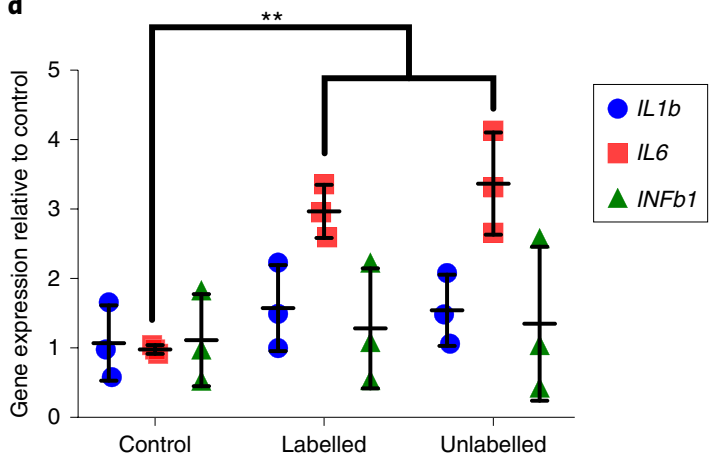

Fig. 2 | Approach to orthogonally label YF prME mRNA with dual radionuclide-near-IR probes. a, Schematic demonstrating mRNA labelling with radionuclide-near-IR probes. b, Immunofluorescence analysis of protein expression in HeLa cells after Lipofectamine 2000 transfection with YF prMEencoding mRNA. Scale bars, $45 \mu \mathrm{m}$. c, Quantification of immunofluorescence analyses demonstrating the efficient translation of both YF prME mRNA labelled with DOTA-DyLight 680 and the corresponding unlabelled mRNA. The results were not statistically different (n.s.) based on a Mann-Whitney test; the mean and s.d. are shown in red; $n=30$. d, Quantitative PCR analysis of gene expression demonstrates no differential activation between labelled and unlabelled mRNA of innate immune response genes (ILIb, IL6 and IFNb1) in HeLa cells $28 \mathrm{~h}$ after transfection. The experiment was repeated twice in triplicate with similar results. The mean and s.d. are represented. **, significant difference by two-way analysis of variance (ANOVA) with Tukey's multiple comparison test.

injection site and iliac LN at 4 and $28 \mathrm{~h}$ post vaccination, after equal contrast enhancement (Fig. 5a). For each anatomical area, a region of interest (ROI) was circumscribed based on high-pass thresholding above the lowest $28 \%$ of signal. The integrated SUV values across these ROIs were reported for each organ (Fig. 5b). The total signal at the injection site was an order of magnitude higher than in any of the draining LNs for all time points. In general, the total SUV of a given LN was inversely correlated with its Euclidian distance from the injection site (that is, inguinal, iliac, then para-aortic LN).

The signal changes over time for inguinal and iliac LN were statistically significant $(P<0.05$; see Methods for calculations). The average decrease in total SUV was $45 \%$ in the muscle at the injection site, whereas the draining LNs showed average increases of $1.5 \times$, $1.9 \times$ and $1.4 \times$ in the inguinal, iliac and para-aortic LNs, respectively (Fig. 5c). To achieve accurate comparisons across time, background levels in the contralateral muscles were used to normalize the absolute SUVs and account for any instrument parameter differences during image acquisition.
In vivo imaging of the radiolabelled mRNA by PET-CT demonstrated that following i.m. injection, mRNA reaches draining LNs relatively quickly and continues to accumulate for at least $28 \mathrm{~h}$ after injection. Notably, the iliac LN of AF031 was distinct from the other LNs, with detectable yet extremely low total SUV values. Nevertheless, the sensitivity and high dynamic range of PET imaging allowed for quantification over time. This result may be due to the i.m. injection for this animal being markedly medial and peripheral compared with the other injection sites (Fig. 4). As such, the iliac LN of AF031 was used to estimate the sensitivity of PET-CT imaging to be $15.4 \mathrm{ng}$ mRNA cm$~_{-3}$ (see Methods for calculations).

Two of the animals were euthanized $28 \mathrm{~h}$ post injection and the experimentally relevant tissues were selectively extracted during necropsy with the help of a portable near-IR camera. In general, we observed that for each anatomical region, a single node of a chain was positive for mRNA signal, whereas the other nodes were negative (Fig. 6a). Interestingly, a resected inguinal node contained only one well-demarcated portion of its volume that was positive 
a
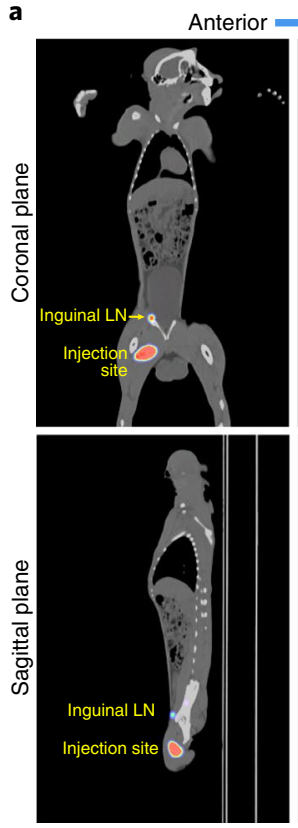

Lateral

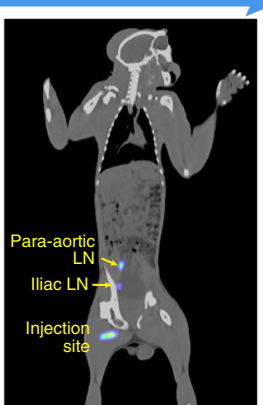

Posterior
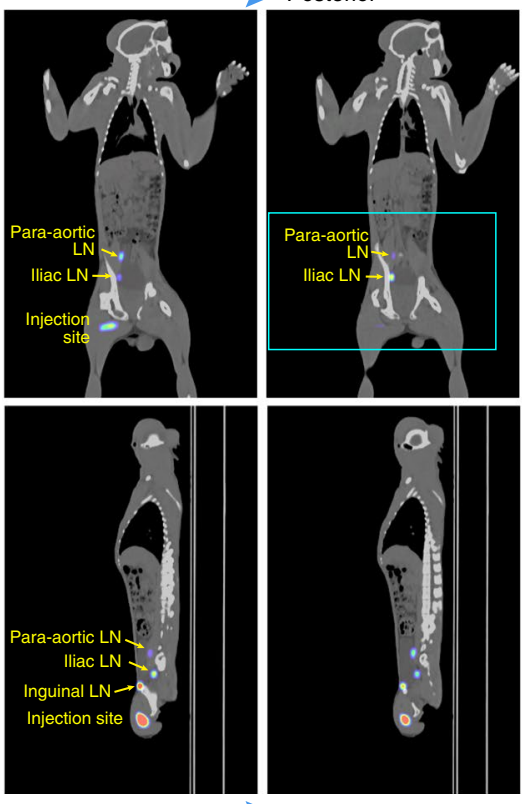

Medial b

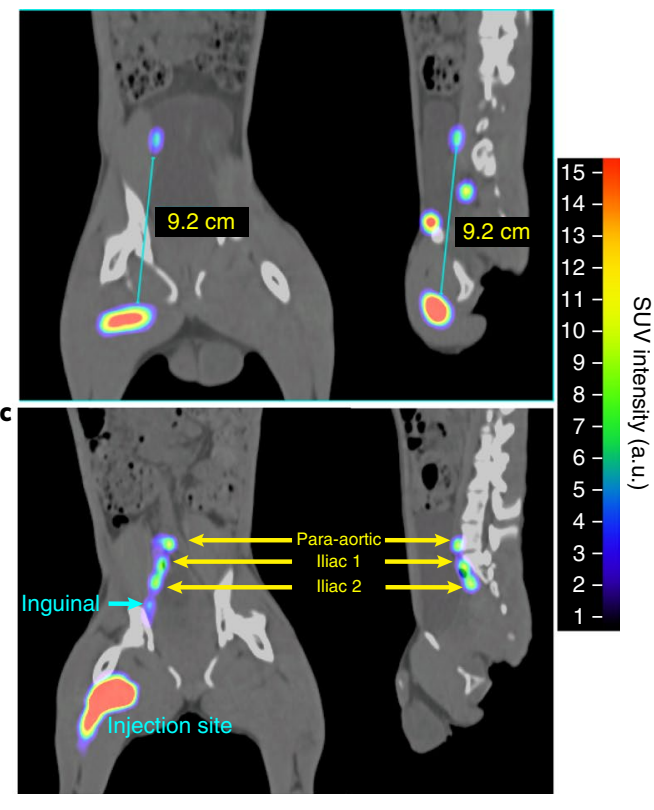

Fig. 3 | Representative PET-CT images of non-human primates $4 \mathrm{~h}$ after i.m. ${ }^{64} \mathrm{Cu}$ vaccine delivery. $\mathbf{a}$, Whole-body coronal and sagittal plane PET-CT images of animal AF032 $4 \mathrm{~h}$ after vaccine delivery. The injection site in the quadriceps and three LN clusters-inguinal, iliac and para-arotic-display SUVs above background levels. All of the sections are equally contrasted. $\mathbf{b}$, An expanded view of the coronal (left) and sagittal (right) PET-CT images of the anatomical region indicated in the blue rectangle in a for animal AF032 demonstrates a maximum Euclidian distance of $9.2 \mathrm{~cm}$ between the injection site and the most distal node (para-aortic). c, Individual draining LNs within an anatomical LN chain are distinguishable using the appropriate contrast enhancement at $4 \mathrm{~h}$ after vaccine delivery to animal AF032. Four animals were used throughout the study.
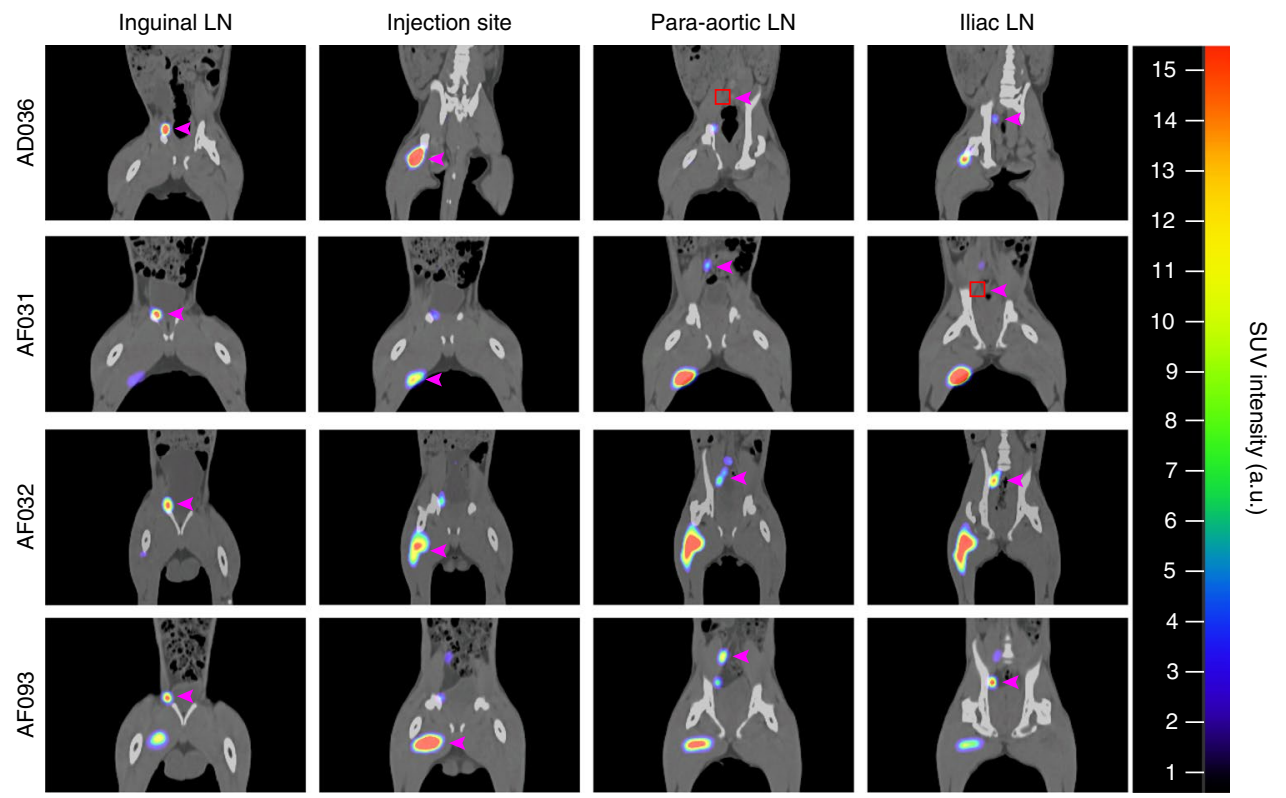

Fig. 4 | PET-CT images of non-human primates $28 \mathrm{~h}$ after i.m. ${ }^{64} \mathrm{Cu}$ vaccine delivery. PET-CT fusion images of each animal at $28 \mathrm{~h}$ post injection, for all four anatomical regions with SUV signal above background. All images are contrasted equally, according to the scale bar. The magenta arrowheads indicate the organ specified by the column header. A red square inscribes the organ of interest in cases when the signal was too low to be visible. Four animals (AD036, AF031, AF032 and AF093) were used throughout the study.

for mRNA signal (Supplementary Fig. 1). These tissues were subsequently processed for immunofluorescence imaging.

Evaluating the stability of dual labelling by PET-CT. We next assessed the stability of dual radionuclide-near-IR mRNA labelling to confirm that the systemic events observed with whole-body PET-CT are indicative of actual mRNA trafficking and not of potential probe dissociation. To achieve this, we measured the following, all in the same animal: (1) total SUV signal from PET within individual organs, (2) near-IR fluorescence status of those organs 


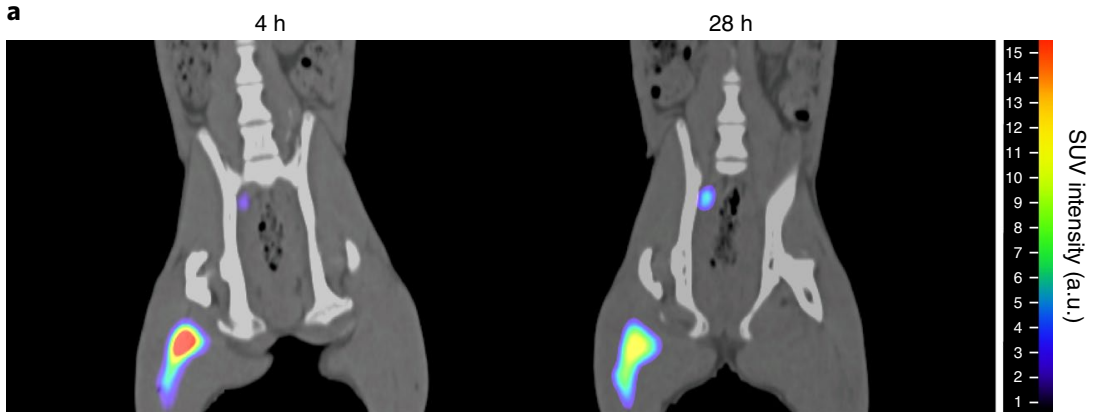

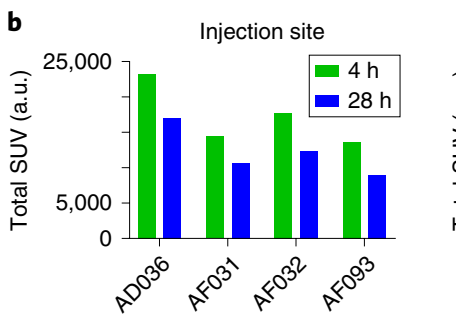

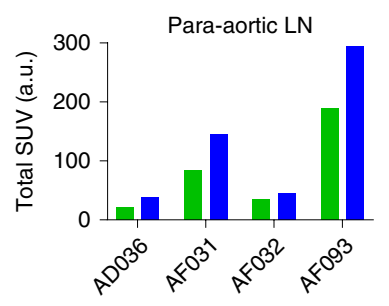

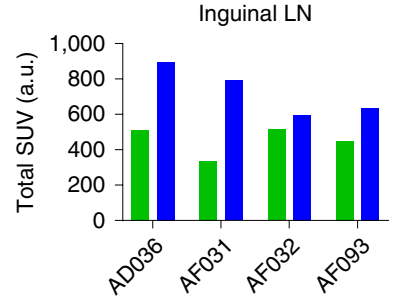

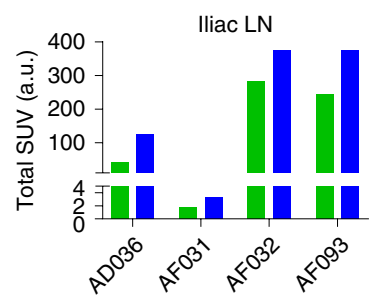

C

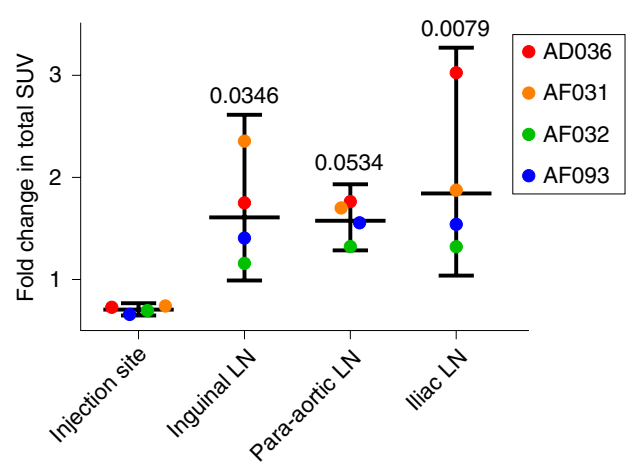

Fig. 5 | Total SUV increases over $\mathbf{2 8} \mathbf{h}$ in draining LNs. a, Visual representation of the changes in SUV signal observed in animal AFO32 from $4 \mathrm{~h}$ (left) to $28 \mathrm{~h}$ (right) after vaccination. The maximum SUV decreased at the injection site and increased in a draining iliac LN with time. $\mathbf{b}$, Absolute SUV intensity values at the different anatomical regions of each animal $(n=4)$ at 4 and $28 \mathrm{~h}$ post vaccination. Note that although the absolute values vary across regions, the signal generally increased in LNs and decreased at the injection site. c, Fold change in total SUVs over $28 \mathrm{~h}$. The horizontal lines designate the median and the error bars represent the $95 \%$ confidence interval. The numbers represent the adjusted $P$ values of comparisons to the injection site obtained by one-way ANOVAs with Dunnett's test for multiple comparisons.

(positive/negative), (3) radioactivity measured with a well counter, (4) percentage of near-IR-positive cells and (5) the number of activated cells, reflective of innate immune stimulation.

To this end, one additional cynomolgus monkey (CM653) was injected with $200 \mu \mathrm{g}(1.26 \mathrm{mCi}$ in a total volume of $500 \mu \mathrm{l}$ Ringer's lactate solution) near-IR and radiolabelled YF prME mRNA formulated with CholK. Whole-body PET-CT imaging was performed $24 \mathrm{~h}$ post injection in a clinical grade scanner, revealing the previously observed trafficking pattern from injected muscle to ipsilateral iliac, inguinal and para-aortic LNs (see Supplementary Table 1 for the total SUV values). The animal was subsequently euthanized and a near-IR portable camera was used at the time of necropsy to identify putative mRNA-positive tissues. The injected muscle, ipsilateral para-aortic and iliac LNs were isolated. The contralateral organs (left side) were collected as controls. The radioactivity of the collected tissues was measured in a well counter and subsequently analysed by flow cytometry to quantify the percentage of labelledmRNA-positive cells and the number of activated intermediate monocytes (Supplementary Fig. 2).

A correlation matrix between these variables in Supplementary Table 1 reveals significant positive linear relationships between the total SUV value and the radioactivity (coefficient of multiple correlation $\left.(R)=1.000, P=1.2 \times 10^{-4}\right)$ and the percentage of nearIR positive cells $(R=0.9638, r=0.0362)$. Increased activation of intermediate monocytes was also observed in the injected muscle and ipsilateral LNs. These results solidified our confidence that the oligo-based probe remained associated with the YF prME mRNA, indicating that the PET-CT whole-body tracking is reflective of mRNA trafficking. Furthermore, these data underscore the value of co-opting ultrasensitive PET imaging for whole-body trafficking of mRNA, as SUV signal was measured in LNs that did not register positive with near-IR imaging or flow cytometry analyses.

Professional APCs uptake mRNA in muscle and draining LNs. We next investigated which cell types were involved with mRNA processing in both muscle and LNs. Three flow cytometry panels were designed and optimized to identify $\mathrm{T}$ and $\mathrm{B}$ cells and subtypes of monocytes and dendritic cells, while allowing for efficient detection of the fluorescently labelled mRNA (Supplementary Tables 2,3 and Figs. 3-5). Analysis of the injected muscle revealed significant recruitment of infiltrating immune cells with respect to its contralateral counterpart (left muscle), prevalently monocytes (classical, non-classical and intermediate) and dendritic cells (conventional and plasmacytoid; Fig. 6b), which is in line with previously reported observations ${ }^{23}$.

To investigate trafficking to LNs, flow cytometry was performed on the extracted para-aortic LN to determine which cell types contained labelled mRNA and whether the presence of labelled mRNA correlated with immune cell activation. We found that antigen-presenting cells (APCs), particularly monocytes, contained the majority of the labelled mRNA in the muscle and LN (Fig. 6c). Analysis of the para-aortic LNs revealed that dendritic and B cells accounted for the predominant labelled-mRNApositive population (Fig. 6d). With regards to cellular activation, 
a
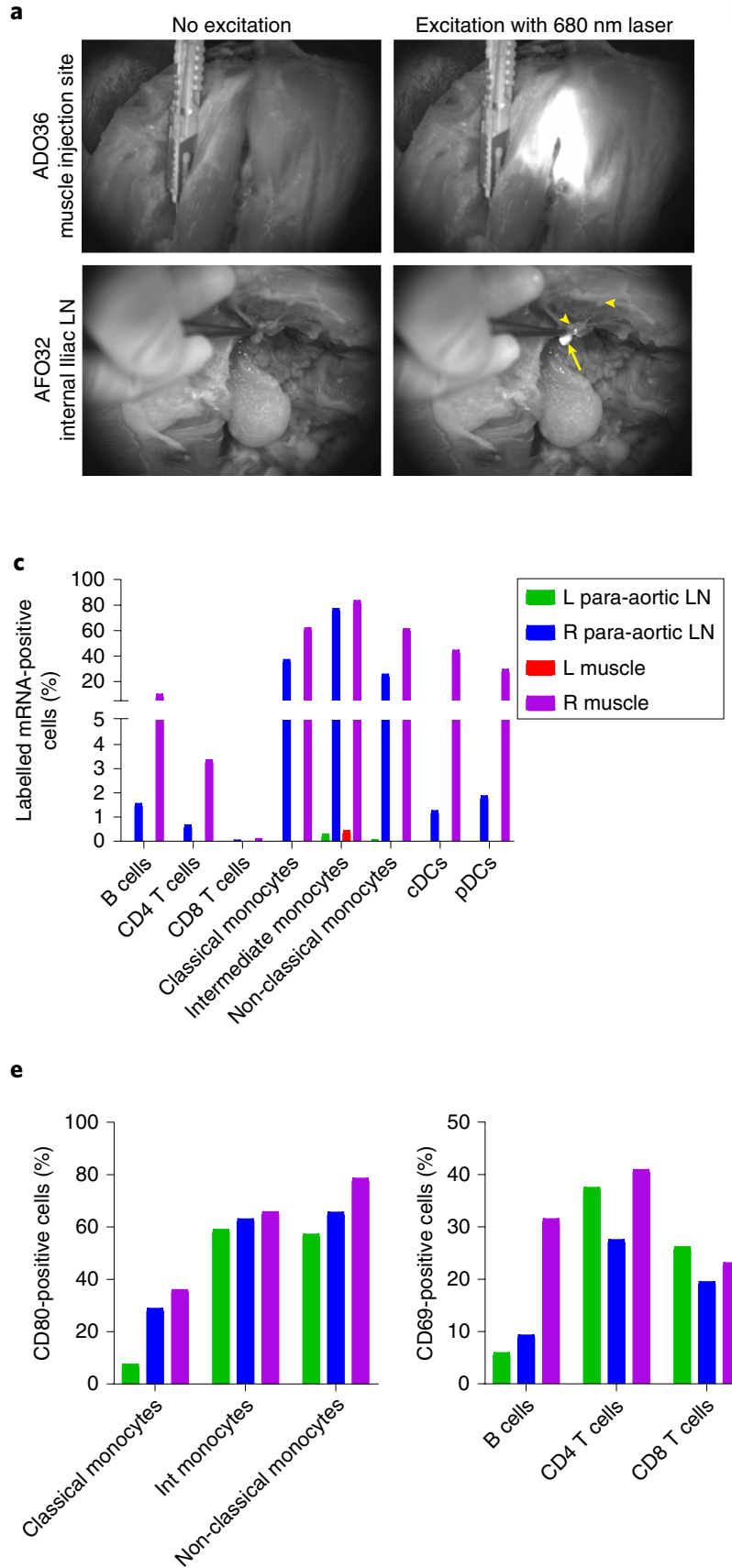

b

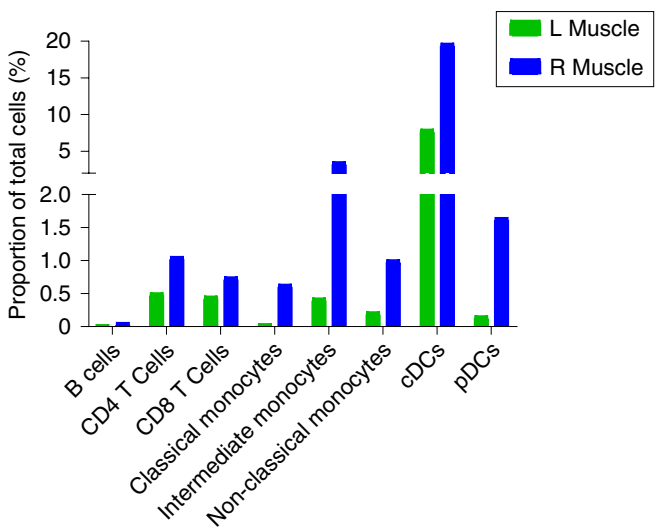

d

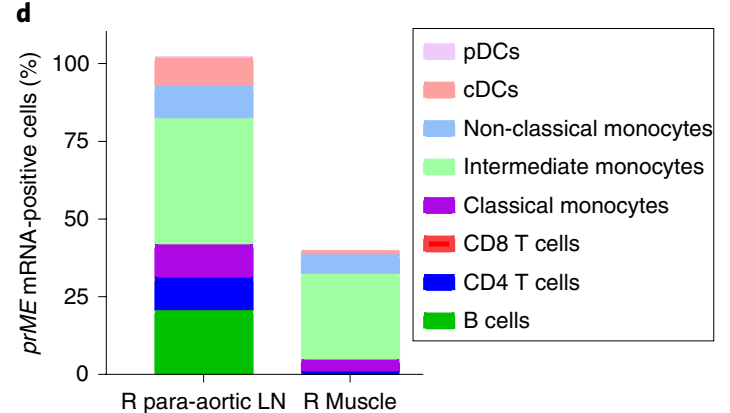

R para-aortic LN R Muscle

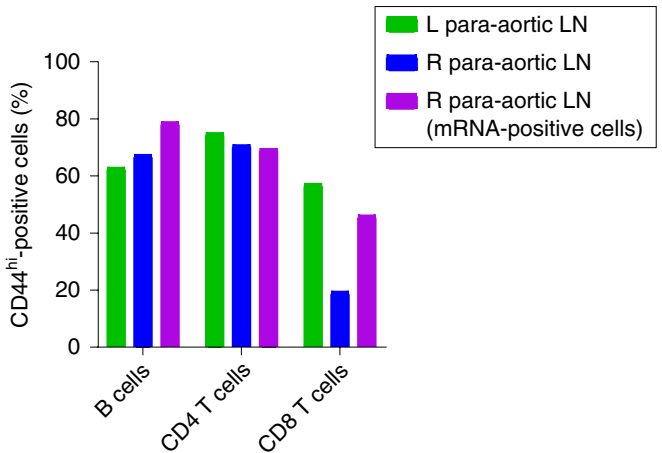

Fig. 6 | APCs are the primary cell type containing radiolabelled prME mRNA in muscle and LNs. a, At the time of necropsy, a portable near-IR imager was used to identify the mRNA-positive tissues. The arrow represents a positive LN and the arrowheads point to the nearby mRNA-negative LNs. The contralateral organs were processed in parallel as negative controls. All laser power and exposure times were empirically determined by minimizing the background on the negative controls. $\mathbf{b}$, Infiltrating immune cells were quantified in the right (injected) and left (contralateral) muscle samples. The bars represent the absolute values. c, Uptake of radiolabelled mRNA according to cell type. The samples were gated for cell type followed by mRNA uptake to determine the percentage of each cell type containing labelled mRNA. Path a of the gating strategy was used for each of the three flow cytometry panels (Supplementary Figs. 3-5). The bars represent the absolute values. d, Cell-type breakdown of labelled mRNA-positive cells. Right para-aortic and right muscle samples were gated for mRNA uptake followed by cell-type markers to determine the frequency of mRNA-positive cells according to cell type. Path $b$ of the gating strategy was used for each of the three flow cytometry panels (Supplementary Figs. 3-5). e, Left and right para-aortic LN samples were analysed for activation markers among all monocytes and B, CD4 T and CD8 T cells. Cells in the right para-aortic LN that were positive for mRNA were also analysed for activation markers. The bars represent the absolute values. L, left; $R$, right.

surface expression of CD80, CD69 and CD44 was observed for monocytes and B cells (Fig. 6d), particularly in the mRNA-positive subset. Although these results were obtained on flow cytometry analyses performed on a single animal, they are in overall agreement with previously reported data ${ }^{23}$. We next sought to examine mRNA distribution and protein expression at the tissue and cellular level via confocal microscopy.

Expression of prME protein with mRNA uptake in muscle and LNs. Two animals (AF032 and AF036) were euthanized $28 \mathrm{~h}$ post 
injection and the experimentally relevant tissues were extracted during necropsy with the help of the portable near-IR camera. Portions of the tissues (positive and negative) were cryopreserved as whole tissues. The spatial distribution of both administered fluorescently labelled YF prME mRNA and expressed prME protein within the extracted organs was investigated through immunofluorescence microscopy. Yellow fever prME protein expression in the LN was confirmed by staining with two different polyclonal antibodies (Supplementary Fig. 6).

Stitched cross-sectional low magnification images of iliac LN (Fig. 7a) and skeletal muscle (Supplementary Fig. 7) indicated that, as expected, mRNA retained its translational capacity, as evidenced by protein staining with respect to sham controls (Supplementary Fig. 8). In the iliac LN, the prME antigen was mainly concentrated in the region of the subcapsular sinus, whereas the mRNA was distributed immediately outside the trabecular sinuses, near the periphery of the well-demarcated germinal centres (Fig. 7a). The large quantity of antigen detected on the external edges of the LN could be representative of secreted (that is, non-cell encapsulated) antigen transport through lymphatics ${ }^{24,25}$.

At higher magnifications, line profile analyses on LN samples indicated that the mRNA fluorescence signal spatially overlapped and correlated with staining of the prME antigen and the representative immune-cell markers CD86 (APCs), CD20 (B cells), CD11c and CD123 (dendritic cells), and CD4 (T cells; Fig. 7b,c and Supplementary Fig. 9). A similar analysis was performed for muscle samples (Supplementary Figs. 10 and 11), where colocalization between mRNA and encoded protein was assessed in tissues sections stained for specific cell markers including dendritic cells (CD11c), macrophages and monocytes (CD11b), APCs (CD86) and $\mathrm{T}$ cells (CD4).

\section{Discussion}

Non-invasive whole-body imaging technologies (that is, luminescence) are less applicable to large mammals, due to size constraints as well as being optically thick. As a result, during vaccine development, an assumption is often made that the delivery distributions observed in lower animal models reliably translate to non-human primates and, ultimately, to humans. The PET-CT tracking data presented here demonstrate a quantitative, tomographic and sensitive method to longitudinally follow mRNA trafficking after delivery in an in vivo setting in non-human primates. The estimated fundamental resolution limit for clinical and preclinical PET scanners is 1.83 and $0.67 \mathrm{~mm}$, respectively ${ }^{26}$. According to our experimental data, we estimate the sensitivity to be $15.4 \mathrm{ng} \mathrm{mRNA} \mathrm{cm}{ }^{-3}$. Based on this sensitivity and ${ }^{64} \mathrm{Cu}$ half-life of $12.7 \mathrm{~h}$, it is reasonable to expect signal above background for at least $4 \mathrm{~d}$ (or 7.6 half-lives) post administration. In addition, PET scanners are a staple of most hospitals and are thus relatively available as a resource for translational studies.

At $4 \mathrm{~h}$ post i.m. vaccine administration, labelled mRNA was present in three draining LN anatomical regions. Over a $28-\mathrm{h}$ period, the signal increased in the draining LNs by an average of $70 \%$, whereas mRNA in the muscle injection site decreased by $40 \%$. Cellular analysis of near-IR-positive tissues $28 \mathrm{~h}$ post injection demonstrated translation of the encoded protein. This robust technology allowed us to visualize, in the five monkeys of this study, mRNA trafficking to the draining LNs and to quantify differences in mRNA uptake, which may be a consequence of experimental variations during injection. The route of vaccine injection, dose, timing and formulations are known to influence mRNA trafficking and, ultimately, the elicited vaccine-specific responses ${ }^{23,27}$.

During necropsy, near-IR signal from the dual-labelled probes was used to extract relevant portions of organs that contained the RNA of interest. We believe that the use of a dual-screening approach is critical to achieve high signal-to-noise and to mitigate sampling errors, particularly in the case where cell types present at low frequencies are being investigated (that is, antigen-specific CD8 cells and dendritic cells). In addition, blind sampling of only the superficially accessible LNs may hamper investigations during clinical studies.

Analysis through flow cytometry allowed us to characterize the following at the single-cell level: (1) the population of immune cells infiltrating the muscle, (2) mRNA uptake by different cell types in the muscle and draining LNs and (3) immune cell activation due to mRNA uptake. Stitched images of the whole $\mathrm{LN}$ at $28 \mathrm{~h}$ post i.m. injection indicated that the mRNA was spatially located just outside the B cell follicles, whereas YF prME antigen was observed in the interior of the germinal centres.

The proposed imaging technology is inherently flexible and modular, with regards to both the protein that is encoded by the mRNA and the carrier that encapsulates the mRNA cargo. Labelling the mRNA directly (that is, before encapsulation) allows this technique to be used with any carrier or delivery system. In this study, the nanoparticle CholK was selected because aminoglycosides are natural compounds that are known to interact specifically with RNA structures. However, any nanoparticle could be utilized in practice. Furthermore, the technical hurdle to label DNA in an analogous manner is minimal. This allows head-to-head comparisons between vaccine formulations of interest to be conducted.

A question that remains to be answered is the degree to which protein expression in the muscle is a determining factor in subsequent antigen-specific immune responses. Producing an innate immune response in the muscle is beneficial due to the potent production of chemokines and cytokines that recruit immune cells ${ }^{28,29}$, but it is possible that the primary consequence of this in terms of vaccine efficacy is increased antigen transport to LNs where antigen presentation to $\mathrm{T}$ helper cells and costimulatory molecule activation occurs ${ }^{30-32}$. In this study, we observed prME expression in the muscle and general recruitment of APC immune cells to the injection site. In the LNs, professional APCs were the primary cell types containing labelled mRNA.

The transport of vaccine components to secondary lymphoid tissue can occur in a passive manner that is driven by convective forces or in an active, cell-mediated manner by APCs that infiltrate the tissue due to cytokine- and chemokine-signalling gradients brought about by inflammation ${ }^{30}$. Passive convection occurs in minutes to hours after delivery, whereas active transport is on the order of hours to days. However, these two modes of antigen delivery to lymphoid tissue are not equivalent and there is evidence that antigen presentation without cellular activation contributes to tolerance ${ }^{30}$. Although we are not able to resolve which transport mechanisms are primarily responsible using this approach, the strong draining LN signal we observed at $4 \mathrm{~h}$ suggests that imaging 30-60 min after injection could help delineate the transport mechanism.

A barrier slowing down effective vaccine development is the empirical manner in which vaccines are evaluated, in a trial-anderror fashion, without a detailed understanding of the reasons they worked in the first place ${ }^{4}$. The parameters of a given vaccine, including adjuvant, delivery vehicle and route of administration, each have profound impacts on the type of immune response generated and subsequent vaccine efficacy ${ }^{33}$. With each vaccination approach having its advantages and disadvantages based on the treatment setting, understanding and reverse engineering the spatio-temporal kinetics of successful vaccines could allow for the rational development of vaccines that share similar trafficking characteristics. In other words, knowing the 'why' and 'how' of a successful vaccine can aid in improving the efficacy of other less efficacious vaccines.

Although beyond the scope of this study, linking acute vaccine trafficking events with downstream adaptive immune responses, in comparison with what is observed in lower animal models, has the potential to shed light on critical spatio-temporal determinants of vac- 
a
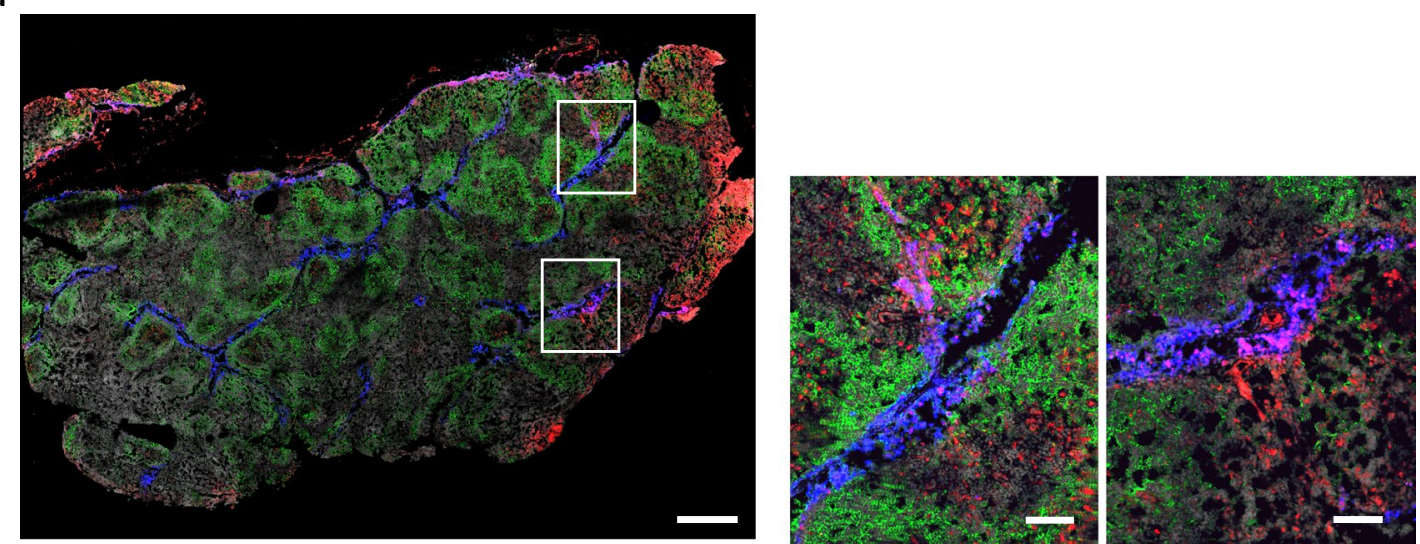

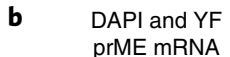
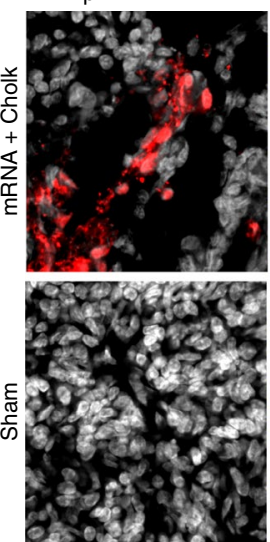

DAPI and YF
prME mRNA

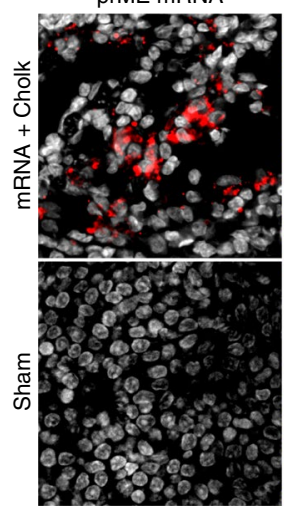

CD20
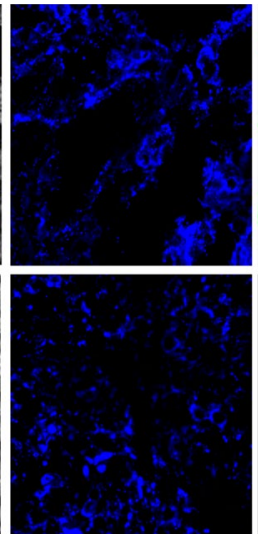

CD86

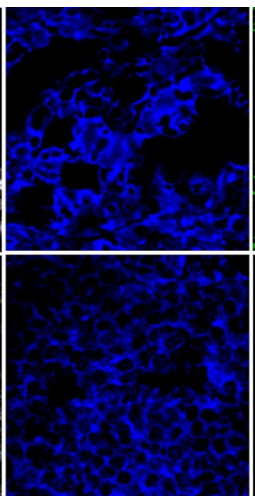

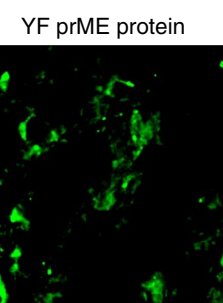
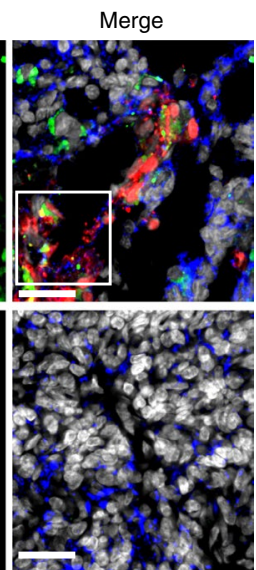

Merge

YF prME protein
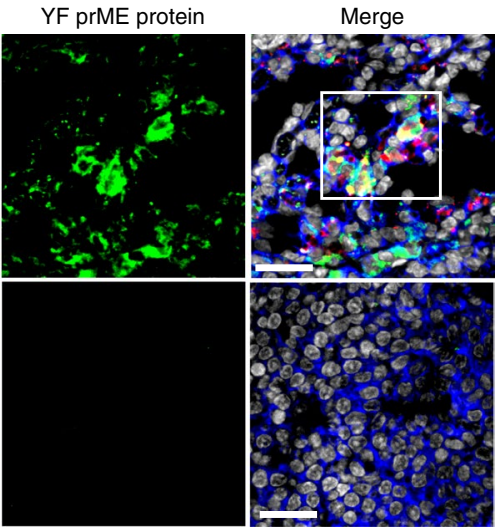
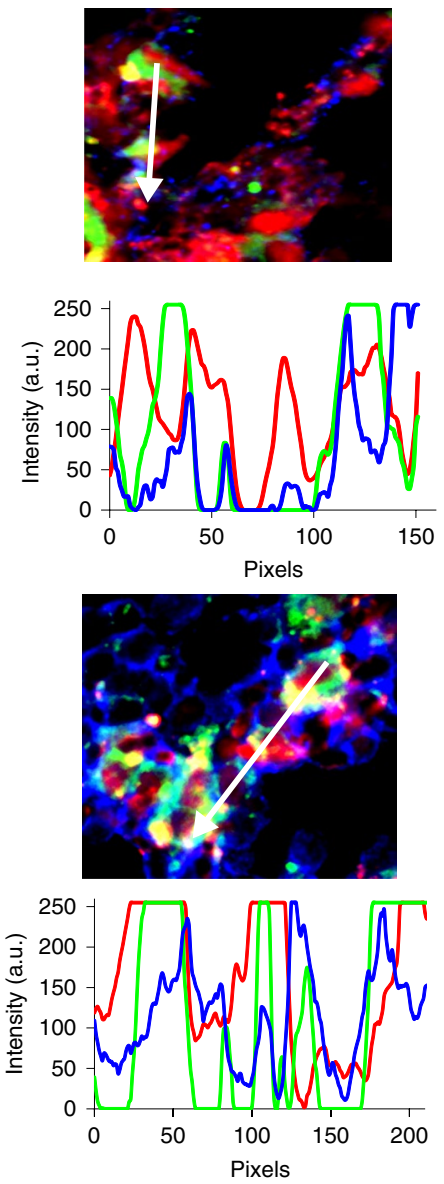

Fig. 7 I YF prME mRNA and protein expression in LNs. a, A whole-organ stitch of an ipsilateral LN from animal AF032 at $\times 20$ magnification. YF prME mRNA (blue) appears in the cortical sinus and trabeculae, whereas expressed protein (red) is predominately, but not exclusively, located on the cortical sinus of the LN. The section was also stained for CD20 (green) and DAPI (white). Scale bar, $500 \mu$ m. Magnifications of the areas boxed in white are shown on the right; Scale bars, $100 \mu \mathrm{m}$. b,c, Sections of LN tissue were stained with the immune cell markers CD20 (b) and CD86 (c), YF prME protein and counterstained for DAPI (white). The sham controls from uninjected monkeys are shown. The images were acquired with a Zeiss 780 confocal microscope with a $\times 40$ objective. Scale bars, $30 \mu \mathrm{m}$. The line profiles (bottom right) obtained along the white arrows for the cropped images (top right) indicate the mRNA in red, cell markers in blue and protein in green. Representative images are shown $(n=3)$.

cine efficacy. The early sequelae following injection of vaccine formulations determine the nature and magnitude of downstream adaptive immune responses ${ }^{34-36}$. This information could be used to correlate vaccine efficacy with trafficking patterns in the days immediately following injection. Generating such a predictive model could help save time, financial resources, lower animal numbers and, in the long-term, provide a rapid proxy for vaccine efficacy during emerging outbreaks or military contexts where verifying immunity quickly is vital. Due to its non-invasive nature, we believe the presented vaccine monitoring approach can help reveal spatio-temporal determinants of vaccine efficacy in preclinical and translational vaccine studies, particularly in large mammals where safety is paramount. 


\section{Methods}

IVT-mRNA labelling. The IVT mRNA encoding YF prME was provided by CureVac AG. It included a 5' cap, the 3' UTR from human albumin as well as a poly(A) tail. MTRIPS for mRNA labelling were synthesized as previously described $^{20-22}$. Briefly, 2' O-methyl RNA-DNA chimeric oligonucleotides 15-17 nucleotides in length containing three or four amino-modified thymidines, a short poly $(\mathrm{T})$ linker and a $5^{\prime}$ biotin (Biosearch Technologies) were purchased. Three oligonucleotides (termed CV1, CV2 and CV3) complementary to sequences in the human albumin $3^{\prime}$ UTR of the mRNA were used for annealing. The oligonucleotides were labelled with DyLight 680-NHS esters (Pierce) using the manufacturer's protocols and excess dye was removed using $3 \mathrm{kDa}$ centrifugal filters (Millipore).

The NeutrAvidin core for MTRIPS assembly was conjugated to DOTA-NHS ester $(5 \times$ molar excess) in $0.1 \mathrm{M}$-phosphate chelexed buffer and excess DOTA was removed using $10 \mathrm{kDa}$ filters. For radioactive labelling, NeutrAvidin-DOTA was incubated with ${ }^{64} \mathrm{Cu}$ in ammonium acetate for $1 \mathrm{~h}$. Unbound ${ }^{64} \mathrm{Cu}$ was removed using $10 \mathrm{kDa}$ filters. Finally, NeutrAvidin-DOTA was separately incubated with each fluorescently labelled oligonucleotide at a 1:5 molar ratio for $1 \mathrm{~h}$ at room temperature (RT). Excess oligonucleotides were removed using $30 \mathrm{kDa}$ filters. For mRNA labelling with MTRIPS, $800 \mu \mathrm{g}$ mRNA was first heated at $75^{\circ} \mathrm{C}$ for $10 \mathrm{~min}$ (to remove secondary structure) and immediately placed on ice for $2 \mathrm{~min}$. MTRIPS were added to the mRNA and incubated at $37^{\circ} \mathrm{C}$ for $2 \mathrm{~h}$. The mRNA-to-MTRIPS ratio was optimized to 1:0.5, which ensured efficient mRNA labelling while avoiding the need for a final purification step by filtration. The resulting labelled mRNA was tested via HPLC (data not shown).

Animals and i.m. injection. Cynomolgus monkeys were used in this study $(n=5$ : AD036, 8.4 kg; AD031, 6.6 kg; AF032, 7.65 kg; AF093, $6.35 \mathrm{~kg}$, all males aged 9; and CM653, $9.6 \mathrm{~kg}$, male aged 12). The macaques were maintained in accordance with the regulations of the Guide for the Care and Use of Laboratory Animal at New Iberia Research Center, University of Louisiana. Each animal was injected intramuscularly in the right quadriceps with $500 \mu \mathrm{l}$ Ringer's lactate solution formulation CholK (In-Cell-Art) with YF IVT prME mRNA labelled with MTRIPS composed of DyLight 680 -oligonucleotides conjugated to ${ }^{64} \mathrm{Cu}$-NeutrAvidin. The total radioactivity injected was $0.7-0.9 \mathrm{mCi}$. Radioactive animals were housed in a separate, designated room, according to $\mathrm{EH} \& \mathrm{~S}$ policies, with daily radioactivity measures, until ten half-lives had elapsed $\left(5.3 \mathrm{~d}\right.$ for $\left.{ }^{64} \mathrm{Cu}\right)$

PET-CT imaging of non-human primates and image analysis. Four animals were imaged at 4 and $28 \mathrm{~h}$ post injection, or $24 \mathrm{~h}$ post injection where indicated, on a clinical grade PET-CT scanner (Siemans Biograph 40) at Our Lady of Lourdes Regional Medical Center. The specific PET parameters used during acquisition can be requested from the corresponding author.

All quantitative software analysis was completed from DICOM-formatted images using MIM Software Inc. A high-pass thresholding filter set at $28 \%$ (that is, only the highest $72 \%$ of the signal within a given region) was used to assign ROIs to each LN. These volumetric regions of interest were used to report the average, maximum and total SUVs. The volume of the ROIs for a given LN never varied by more than $5 \%$ across time points. To account for instrument parameters that might have altered between imaging sessions, contralateral muscle SUV average values for a circumscribed ROI were used to normalize readings. The video clip displaying a three-dimensional reconstruction of the PET-CT data was accomplished using Amira software (Thermo Fisher Scientific).

PET sensitivity estimation of mRNA. The iliac LN of AF031 was used to estimate the sensitivity of PET-CT to quantify mRNA, as it was the lowest, yet detectable, organ able to be quantified. The calculations that follow are based on the SUV values for this iliac LN and an initial injection quantity of $200 \mu \mathrm{g}$ mRNA. Assuming a closed system (that is, no RNA enters the blood circulation), then the amount of mRNA indicated by an SUV of 1.72 is $36.3 \mathrm{ng}$. This iliac LN signal is 11.80 -fold greater than that found in an equal volume of control muscle tissue. If we assume a detection sensitivity $2 \times$ higher than the background, then the sensitivity of detection is $6.16 \mathrm{ng}$ for a volume of $0.4 \mathrm{ml}$ (or $\left.15.4 \mathrm{ng} \mathrm{cm}^{-3}\right)$.

Tissue extraction, near-IR imaging and flow cytometry. One animal was euthanized at $16 \mathrm{~h}$ post vaccine administration. During necropsy, muscle tissues and LNs were screened for near-IR signal using the Fluobeam near-IR portable camera (Fluoptics Imaging Inc.) and the radioactive signal was measured using a well counter. Contralateral tissues were also collected as negative controls. Excised LNs were mechanically dissociated by pressing and grinding the tissue over a $70 \mu \mathrm{m}$ filter and a $40 \mu \mathrm{m}$ filter (BD Biosciences) fitted on top of a $50 \mathrm{ml}$ conical tube. During mechanical disruption, the tissue was systematically washed with RPMI1640 media with 10\% Pen/Step under sterile conditions. The muscle tissues were cut into small pieces and digested with $0.2 \%$ Type IV collagenase (Worthington) and $0.01 \%$ RQ1 DNase (Promega) for $90 \mathrm{~min}$ at $37^{\circ} \mathrm{C}$ with gentle shaking. Digested muscle tissues were passed through a $15 \mathrm{G}$ blunt followed by an $18 \mathrm{G}$ blunt needle several times. The tissues were subsequently filtered through a $70 \mu \mathrm{m}$ and a $40 \mu \mathrm{m}$ strainer. The cells were centrifuged at $1,000 \mathrm{~g}$ for $10 \mathrm{~min}$ at $4^{\circ} \mathrm{C}$; the resultant cell pellet was treated with ACK solution for $5 \mathrm{~min}$ for red-blood-cell lysis and washed with RPMI medium. The cells were resuspended in $10 \mathrm{ml}$ complete RPMI, counted with a haemocytometer and immediately processed for flow cytometry. One million cells were stained with the cell-type markers indicated in Supplementary Tables 2 and 3. Surface cell staining was performed in FACS wash buffer ( $2 \%$ fetal bovine serum in $1 \times \mathrm{PBS})$. The cells were fixed with $1 \%$ paraformaldehyde in FACS wash at $4{ }^{\circ} \mathrm{C}$ until data acquisition. Cells were gated as indicated in Supplementary Figs. 2-5. All samples were acquired using a FACSAria Fusion (BD Biosciences). All analysis was performed using the FlowJo software package (Tree Star). A minimum total of 300,000 events were recorded for each organ.

Tissue extraction, near-IR imaging and immunohistochemistry. Two of the four animals were euthanized at $28 \mathrm{~h}$ post vaccine administration. During necropsy, muscle tissues and LNs were screened for near-IR signal using the Fluobeam near-IR portable camera (Fluoptics Imaging Inc.). Images were acquired at varying exposure times in low ambient-light conditions. Contralateral tissues were also collected as negative controls. For immunohistochemistry tissue processing, macaque draining iliac or inguinal LNs and muscle (injection site and contralateral), and mouse iliac LN tissues were fixed in $4 \%$ paraformaldehyde overnight at RT. The next day, the tissues were washed once with PBS and incubated with $30 \%$ sucrose in PBS overnight at $4^{\circ} \mathrm{C}$, followed by optimal cutting temperature (OCT) compound embedding. Tissue blocks in OCT were immediately snap frozen in dry-ice-cooled isopentane and stored at $-80^{\circ} \mathrm{C}$. Frozen tissue blocks were sectioned into $10-\mu \mathrm{m}$-tissue sections using a cryostat. Tissue sections separated by $50-100 \mu \mathrm{m}$ were used to stain for the specific immune cell markers and antigenic protein. Macaque LN tissue from a sham animal (uninjected) and contralateral animal were used as controls.

Immunofluorescence tissue imaging. Cynomolgus monkey iliac LN-tissue sections were stained for cell surface markers (Table 4) and expressed YF prME antigen. The slides were thawed in a humidified chamber for $5 \mathrm{~min}$ and washed twice with $1 \times$ PBS. The sections were incubated in $1 \times$ Dako antigen retrieval buffer for $30 \mathrm{~min}$ in a steamer, followed by cooling at RT for $20 \mathrm{~min}$. The slides were washed once with $1 \times$ PBS and permeabilized with PBST (PBS containing $0.1 \%$ Tween 20 ) for $30 \mathrm{~min}$. The tissues were blocked with $10 \%$ donkey serum plus $1 \%$ BSA for $45 \mathrm{~min}$, followed by incubation with the primary antibodies targeting the selected cell-type markers and YF prME protein for $45 \mathrm{~min}$ at RT (the primary antibodies source and dilutions are listed in Table 1). Tissue sections were washed four times with $1 \times$ PBST for 10 min each, followed by incubation with the secondary antibodies (as listed in Table 1) for $30 \mathrm{~min}$. The slides were washed four times with $1 \times$ PBST ( 5 min each) and incubated with DAPI for $5 \mathrm{~min}$ at RT. After two final washes with $1 \times \mathrm{PBS}$, the slides were mounted with $10 \mu \mathrm{l}$ ProLong gold. Muscle-tissue sections were incubated with $1 \times \mathrm{DAKO}$ antigen retrieval buffer for $20 \mathrm{~min}$ and blocked for $1 \mathrm{~h}$ as described previously. The slides were then incubated overnight with primary antibodies to the selected immune cell markers. The next day, the tissue sections were incubated with secondary antibodies for $30 \mathrm{~min}$, followed by three washes with PBST. The YF prME antibody was added for $1 \mathrm{~h}$, followed by three washes with PBST. The nuclei were counterstained with DAPI and the slides were mounted with ProLong Gold.

Tissue sections from LNs and muscles from macaques were imaged with a $\times 40$ oil objective. Three or four slides were imaged for each cell marker and 10-12 images were taken per slide. Stitching was performed using a $\times 20$ objective for LN tissue and a $\times 40$ objective for muscle tissue.

Statistics and image visualization. All statistical tests and graphical figures were generated using GraphPad Prism.

Quantitative RT-PCR for cytokine expression in vitro. Hela cells (ATCC) were cultured in DMEM (Lonza) with $10 \%$ fetal bovine serum (Hyclone), $100 \mathrm{U} \mathrm{ml}^{-1}$ penicillin and $100 \mathrm{ug} \mathrm{ml}^{-1}$ streptomycin (Invitrogen) and were plated one day before the experiments. Cells were transfected with $500 \mathrm{ng}$ of either unlabelled or MTRIP-labelled mRNA in duplicates using Lipofectamine 2000 (L2K, Thermo Fisher Scientific) following the manufacturer's instructions. Vehicle-only controls were included. After transfection $(28 \mathrm{~h})$, cells were processed for total RNA extraction using the RNeasy mini kit (Qiagen). Total RNA was checked for integrity through agarose gel electrophoresis and quantified using a NanoDrop 2000. Total RNA $(1 \mu \mathrm{g})$ was used for complementary DNA synthesis using the RT2 first strand kit (Qiagen) according to manufacturer's instructions. The reaction product $(1 \mu \mathrm{g})$ was used for $\mathrm{qRT}-\mathrm{PCR}$ using the Real-time RT ${ }^{2} \mathrm{qPCR}$ primer assay (SYBR green) in the presence of gene-specific primers for $I L 6, I N F 1 B$, $I L 1 B$ and GAPDH (Qiagen). Quantitative RT-PCR was performed using the ABI StepOnePlus Real-Time PCR system (Applied Biosciences).

Animal ethics. All animal studies were approved by the IACUC committee at the New Iberia Research Center, University of Louisiana at Lafayette and the IACUC at the Georgia Institute of Technology.

Reporting Summary. Further information on research design is available in the Nature Research Reporting Summary linked to this article. 


\section{Data availability}

The authors declare that all data supporting the findings of this study are available within the paper and its Supplementary Information. The PET-CT-scanner acquisition settings are available on request from the corresponding author.

Received: 14 May 2018; Accepted: 28 February 2019; Published online: 1 April 2019

\section{References}

1. Qin, L., Gilbert, P. B., Corey, L., McElrath, M. J. \& Self, S. G. A framework for assessing immunological correlates of protection in vaccine trials. J. Infect. Dis. 196, 1304-1312 (2007).

2. Gilbert, P. B., Qin, L. \& Self, S. G. Evaluating a surrogate endpoint at three levels, with application to vaccine development. Stat. Med. 27, 4758-4778 (2008).

3. DeFrancesco, L. The 'anti-hype' vaccine. Nat. Biotechnol. 35, 193-197 (2017).

4. Pulendran, B. \& Ahmed, R. Immunological mechanisms of vaccination. Nat. Immunol. 12, 509-517 (2011).

5. Verbeke, R. et al. Co-delivery of nucleoside-modified mRNA and TLR agonists for cancer immunotherapy: restoring the immunogenicity of immunosilent mRNA. J. Control. Release 266, 287-300 (2017).

6. Fotin-Mleczek, M. et al. Messenger RNA-based vaccines with dual activity induce balanced TLR-7 dependent adaptive immune responses and provide antitumor activity. J. Immunother. 34, 1-15 (2011).

7. Lonez, C., Vandenbranden, M. \& Ruysschaert, J.-M. Cationic lipids activate intracellular signaling pathways. Adv. Drug Deliv. Rev. 64, 1749-1758 (2012)

8. Pollard, C. et al. Type I IFN counteracts the induction of antigen-specific immune responses by lipid-based delivery of mRNA vaccines. Mol. Ther. 21, 251-259 (2013).

9. Petsch, B. et al. Protective efficacy of in vitro synthesized, specific mRNA vaccines against influenza A virus infection. Nat. Biotechnol. 30, 1210-1216 (2012)

10. Pardi, N. et al. Zika virus protection by a single low-dose nucleosidemodified mRNA vaccination. Nature 543, 248-251 (2017).

11. Benteyn, D., Heirman, C., Bonehill, A., Thielemans, K. \& Breckpot, K. mRNA-based dendritic cell vaccines. Expert Rev. Vaccines 14, 161-176 (2015)

12. Diken, M. et al. Selective uptake of naked vaccine RNA by dendritic cells is driven by macropinocytosis and abrogated upon DC maturation. Gene Ther. 18, 702-708 (2011).

13. Broos, K. et al. Particle-mediated intravenous delivery of antigen mRNA results in strong antigen-specific T-cell responses despite the induction of type I interferon. Mol. Ther. Nucleic Acids 5, e326 (2016).

14. Stoll, S., Delon, J., Brotz, T. M. \& Germain, R. N. Dynamic imaging of T cell-dendritic cell interactions in lymph nodes. Science 296, 1873-1876 (2002).

15. van Aalst, S. et al. Routing dependent immune responses after experimental R848-adjuvated vaccination. Vaccine 36, 1405-1413 (2018).

16. Frey, S. E. et al. Comparison of lyophilized versus liquid modified vaccinia Ankara (MVA) formulations and subcutaneous versus intradermal routes of administration in healthy vaccinia-naive subjects. Vaccine 33, 5225-5234 (2015).

17. Desigaux, L. et al. Self-assembled lamellar complexes of siRNA with lipidic aminoglycoside derivatives promote efficient siRNA delivery and interference. Proc. Natl Acad. Sci. USA 104, 16534-16539 (2007).

18. Habrant, D. et al. Design of ionizable lipids to overcome the limiting step of endosomal escape: application in the intracellular delivery of mRNA, DNA, and siRNA. J. Med. Chem. 59, 3046-3062 (2016).

19. Colombani, T. et al. Self-assembling complexes between binary mixtures of lipids with different linkers and nucleic acids promote universal mRNA, DNA and siRNA delivery. J. Control. Release 249, 131-142 (2017).

20. Kirschman, J. L. et al. Characterizing exogenous mRNA delivery, trafficking, cytoplasmic release and RNA-protein correlations at the level of single cells. Nucleic Acids Res. 45, e113 (2017).

21. Alonas, E., Vanover, D., Blanchard, E., Zurla, C. \& Santangelo, P. J. Imaging viral RNA using multiply labeled tetravalent RNA imaging probes in live cells. Methods 98, 91-98 (2016)

22. Bhosle, S. M. et al. Unifying in vitro and in vivo IVT mRNA expression discrepancies in skeletal muscle via mechanotransduction. Biomaterials 159 189-203 (2018).

23. Liang, F. et al. Efficient targeting and activation of antigen-presenting cells in vivo after modified mRNA vaccine administration in rhesus macaques. Mol. Ther. 25, 2635-2647 (2017)
24. Shustov, A. V., Mason, P. W. \& Frolov, I. Production of pseudoinfectious yellow fever virus with a two-component genome. J. Virol. 81, 11737-11748 (2007)

25. Op De Beeck, A. et al. Role of the transmembrane domains of prM and E proteins in the formation of yellow fever virus envelope. J. Virol. 77, 813-820 (2003).

26. Moses, W. W. Fundamental limits of spatial resolution in PET. Nucl. Instrum. Methods Phys. Res. A 648, S236-S240 (2011).

27. Pauthner, M. et al. Elicitation of robust tier 2 neutralizing antibody responses in nonhuman primates by HIV envelope trimer immunization using optimized approaches. Immunity 46, 1073-1088 (2017).

28. Lu, F. \& HogenEsch, H. Kinetics of the inflammatory response following intramuscular injection of aluminum adjuvant. Vaccine 31, 3979-3986 (2013).

29. Calabro, S. et al. Vaccine adjuvants alum and MF59 induce rapid recruitment of neutrophils and monocytes that participate in antigen transport to draining lymph nodes. Vaccine 29, 1812-1823 (2011).

30. Thomas, S. N., Rohner, N. A. \& Edwards, E. E. Implications of lymphatic transport to lymph nodes in immunity and immunotherapy. Annu. Rev. Biomed. Eng. 18, 207-233 (2016).

31. Wood, K. J., Bushell, A. \& Hester, J. Regulatory immune cells in transplantation. Nat. Rev. Immunol. 12, 417-430 (2012).

32. Ford, M. L., Adams, A. B. \& Pearson, T. C. Targeting co-stimulatory pathways: transplantation and autoimmunity. Nat. Rev. Nephrol. 10, 14-24 (2014).

33. Reed, S. G., Orr, M. T. \& Fox, C. B. Key roles of adjuvants in modern vaccines. Nat. Med. 19, 1597-1608 (2013).

34. Deering, R. P., Kommareddy, S., Ulmer, J. B., Brito, L. A. \& Geall, A. J. Nucleic acid vaccines: prospects for non-viral delivery of mRNA vaccines. Expert Opin. Drug Deliv. 11, 885-899 (2014).

35. Liang, F. \& Loré, K. Local innate immune responses in the vaccine adjuvant-injected muscle. Clin. Transl. Immunol. 5, e74 (2016).

36. Liang, F. et al. Vaccine priming is restricted to draining lymph nodes and controlled by adjuvant-mediated antigen uptake. Sci. Transl. Med. 9, eaal2094 (2017).

\section{Acknowledgements}

The Petit Institute Core at Georgia Tech, particularly S. Durham and A. Shaw, who provided guidance and resources for flow cytometry and confocal microscopy, respectively. This work was supported by the Defense Advanced Research Projects Agency, Sanofi Pasteur and the RNArmorVax Consortium (to P.J.S). The views, opinions and/or findings expressed are those of the author(s) and should not be interpreted as representing the official views or policies of the US Department of Defense or the US Government.

\section{Author contributions}

K.E.L. performed the probe labelling of mRNA, ${ }^{64} \mathrm{Cu}$-reporter labelling, necropsies, near-IR tissue extraction and processing, tissue imaging and quantification, PET-CT data analysis, and wrote the manuscript. S.M.B. performed in vitro transfections, probe labelling and optimization of mRNA labelling, nanoparticle optimization, tissue staining, imaging and quantification, and wrote the manuscript. C.Z. performed optimization of mRNA labelling with probes, HPLC of RNA, RT-PCR of innate gene expression, preparation of samples for flow cytometry, and paper revision and editing. J.B. analysed the flow cytometry data. K.A.R., P.X. and L.M.S. performed the flow cytometry. D.V. and M.A. performed PET imaging and necropsy. B.P. synthesized the CholK nanoparticles. P.B. synthesized the IVT YF prME mRNA. F.V. designed the experiments, and performed PET imaging, animal care and necropsies. P.J.S. designed the experiments, performed probe labelling of mRNA, PET imaging and edited the manuscript.

\section{Competing interests}

B.P. owns stock in In-Cell-Art, which commercializes lipidic aminoglycoside derivatives. P.B. is an employee at CureVac, which commercializes RNA-based vaccines.

\section{Additional information}

Supplementary information is available for this paper at https://doi.org/10.1038/ s41551-019-0378-3.

Reprints and permissions information is available at www.nature.com/reprints. Correspondence and requests for materials should be addressed to P.J.S.

Publisher's note: Springer Nature remains neutral with regard to jurisdictional claims in published maps and institutional affiliations.

(c) The Author(s), under exclusive licence to Springer Nature Limited 2019 


\section{natureresearch}

Corresponding author(s): Philip Santangelo

Last updated by author(s): Feb 21, 2019

\section{Reporting Summary}

Nature Research wishes to improve the reproducibility of the work that we publish. This form provides structure for consistency and transparency in reporting. For further information on Nature Research policies, see Authors \& Referees and the Editorial Policy Checklist.

\section{Statistics}

For all statistical analyses, confirm that the following items are present in the figure legend, table legend, main text, or Methods section.

n/a Confirmed

\The exact sample size $(n)$ for each experimental group/condition, given as a discrete number and unit of measurement

$\bigotimes$ A statement on whether measurements were taken from distinct samples or whether the same sample was measured repeatedly

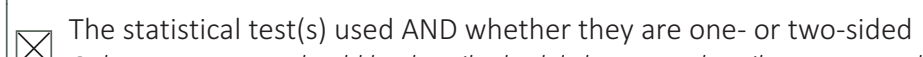

Only common tests should be described solely by name; describe more complex techniques in the Methods section.

$\searrow$ A description of all covariates tested

$\bigotimes$ A description of any assumptions or corrections, such as tests of normality and adjustment for multiple comparisons

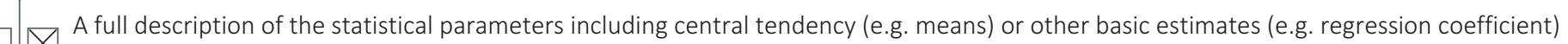

$\triangle$ AND variation (e.g. standard deviation) or associated estimates of uncertainty (e.g. confidence intervals)

For null hypothesis testing, the test statistic (e.g. $F, t, r$ ) with confidence intervals, effect sizes, degrees of freedom and $P$ value noted

$\triangle$ Give $P$ values as exact values whenever suitable.

Х $\square$ For Bayesian analysis, information on the choice of priors and Markov chain Monte Carlo settings

Х $\square$ For hierarchical and complex designs, identification of the appropriate level for tests and full reporting of outcomes

Х $\square$ Estimates of effect sizes (e.g. Cohen's $d$, Pearson's $r$ ), indicating how they were calculated

Our web collection on statistics for biologists contains articles on many of the points above.

\section{Software and code}

\section{Policy information about availability of computer code}

Data collection Volocity (Microscopy acquisiton; PerkinElmer); StepOnePlus (ABI); BD FACSDiva (Flow acquisition); Fluobeam aquisition software (Fluoptics).

Data analysis Volocity (Microscopy analysis; PerkinElmer); StepOnePlus (ABI); FlowJo (Flow analysis); MIM (PET/CT analysis); Amira (PET/CT 3D reconstructions); Graphpad Prism 7 (plotting and statistical analyses).

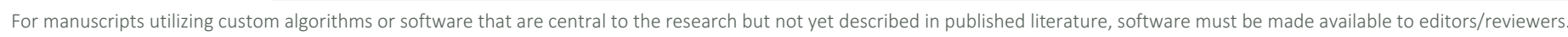
We strongly encourage code deposition in a community repository (e.g. GitHub). See the Nature Research guidelines for submitting code \& software for further information.

\section{Data}

Policy information about availability of data

All manuscripts must include a data availability statement. This statement should provide the following information, where applicable:

- Accession codes, unique identifiers, or web links for publicly available datasets

- A list of figures that have associated raw data

- A description of any restrictions on data availability

The authors declare that all data supporting the findings of this study are available within the paper and its Supplementary Information. PET/CT-scanner acquisition settings are available upon request from the corresponding author. 
Please select the one below that is the best fit for your research. If you are not sure, read the appropriate sections before making your selection. \Life sciences Behavioural \& social sciences Ecological, evolutionary \& environmental sciences

For a reference copy of the document with all sections, see nature.com/documents/nr-reporting-summary-flat.pdf

\section{Life sciences study design}

All studies must disclose on these points even when the disclosure is negative.

Sample size This study did not require pre-specified effect sizes and therefore no sample-size calculations were needed. All in vitro experiments (immunofluorescence in cells and tissues, qPCR) were performed at least twice in triplicates. PET-CT studies were performed in four animals. Probe validation and flow cytometry experiments were performed using samples from one animal.

Data exclusions No data were excluded.

Replication Probe validation and flow-cytometry experiments were not repeated. All other experiments were replicated.

Randomization This study did not require randomization. All animals received the same treatment.

Blinding This study did not require blinding. All animals received the same treatment.

\section{Reporting for specific materials, systems and methods}

We require information from authors about some types of materials, experimental systems and methods used in many studies. Here, indicate whether each material, system or method listed is relevant to your study. If you are not sure if a list item applies to your research, read the appropriate section before selecting a response.

Materials \& experimental systems

$\mathrm{n} / \mathrm{a}$ Involved in the study

Methods

$\square$ 冈 Antibodies

$\square \bigotimes$ Eukaryotic cell lines

\ $\square$ Palaeontology

n/a Involved in the study

X $\square$ ChIP-seq

$\square$ \ Flow cytometry

Ш Palaeontologr

$\bigotimes$ Animals and other organisms

\ $\square$ Human research participants

$\bigotimes \square$ Clinical data

\section{Antibodies}

Antibodies used

All information about the antibodies used in the studies for flow cytometry and immunofluorescence are listed in Supplementary tables $2-4$, including clone, catalogue number and vendor.

Validation Antibodies for immunofluorescence were validated using mock controls or no primary controls. All antibodies for flow cytometry were validated by the manufacturer.

\section{Eukaryotic cell lines}

Policy information about cell lines

Cell line source(s)

HeLA ATCC CCL-2.

Authentication

ATCC cell-line authentication service.

Mycoplasma contamination

Cells were routinely inspected for contamination.

Commonly misidentified lines (See ICLAC register)

No commonly misidentified cell lines were used. 
Policy information about studies involving animals; ARRIVE guidelines recommended for reporting animal research

Laboratory animals

Five Cynomolgus monkeys were used: AD036 8.4 kg, AD031 6.6kg, AF032 7.65 kg, AF093 6.35 kg (all age 9 and males), and CM653 9.6kg, male, age 12.

Wild animals

The study did not involve wild animals.

Field-collected samples

The study did not involve samples collected from the field.

Ethics oversight

Macaques were maintained in accordance with the regulations of the Guide for the Care and Use of Laboratory Animal at New Iberia Research Center, University of Louisiana.

Note that full information on the approval of the study protocol must also be provided in the manuscript.

\section{Flow Cytometry}

Plots

Confirm that:

Х The axis labels state the marker and fluorochrome used (e.g. CD4-FITC).

Х The axis scales are clearly visible. Include numbers along axes only for bottom left plot of group (a 'group' is an analysis of identical markers).

X All plots are contour plots with outliers or pseudocolor plots.

Х A numerical value for number of cells or percentage (with statistics) is provided.

\section{Methodology}

Sample preparation

Instrument

Software

Cell population abundance

Gating strategy
One animal was euthanized at 16 hours post vaccine administration. During necropsy, muscle tissues and lymph nodes were screened for near-IR signal using the Fluobeam near-IR portable camera (Fluoptics Imaging Inc, Cambridge MA), and the radioactive signal was measured using a well counter. Contralateral tissues were also collected as negative controls. Excised LNs were mechanically dissociated by pressing and grinding the tissue on top of a $70 \mu \mathrm{m}$ filter and a $40 \mu \mathrm{m}$ filter (BD Biosciences), fitted on top of a 50-mL conical tube. During mechanical disruption, the tissue was systematically washed with RPMI1640 media with $10 \%$ Pen/Step, under sterile conditions. Muscle tissues were cut into small pieces and digested with $0.2 \%$ Type IV collagenase (Worthington) and 0.01\% RQ1 DNase (Promega) for 90 minutes at 37으, with gentle shaking. Digested muscles were passed through a $15 \mathrm{G}$ blunt followed by an $18 \mathrm{G}$ blunt needle several times. Tissues were subsequently filtered through a $70-\mu \mathrm{m}$ and a $40-\mu \mathrm{m}$ strainer. The cells were centrifuged at $1000 \mathrm{xg}$ for 10 minutes at $4^{\circ} \mathrm{C}$; the resultant cell pellet was treated with $\mathrm{ACK}$ solution for 5 minutes for red-blood-cells lysis and washed with RPMI. Cells were resuspended in $10 \mathrm{ml}$ of complete RPMI, counted with a hemocytometer, and immediately processed for flow cytometry. One million cells were chosen and stained with the cell type markers indicated in Supplementary Tables 2 and 3. Surface cell staining was performed in FACS Wash buffer ( $2 \%$ FBS in $1 \times$ PBS). Cells were fixed with $1 \%$ PFA in FACS Wash at $4^{\circ} \mathrm{C}$ until data acquirement. Cells were gated as indicated in Supplemenary Figs. 2-5. All samples were acquired using a FACSAria Fusion (BD Biosciences). All analyses were performed using the FlowJo software package (Tree Star, Ashland, OR, USA). A total of at least 300,000 events were recorded for each organ.

FACSAria Fusion (BD Biosciences)

Acquisition - BD FACSDiva; Analysis - FlowJo software package (Tree Star, Ashland, OR, USA).

A total of at least 300,000 events were recorded for each experimental condition.

The gating strategy for the main cell types is illustrated and explained in Supplementary figures 3, 4 and 5.

Tick this box to confirm that a figure exemplifying the gating strategy is provided in the Supplementary Information. 